MUSCULO-SKELETAL COMPLICATIONS OF JOGGING

\author{
B. CORRIGAN
}

\author{
1 Lookout Av., DEE WHY, New South Wales, Australia
}

To jog is to move or run at a leisurely pace, but is not without injury risk. The large increase in the number of people engaged in this activity is world wide, thirty million in the USA alone, and this has brought problems, not least commercial exploitation. Although most participants find the activity enjoyable and relaxing, some felt that it is an activity that promotes fitness by first making one crippled. Certain causative factors in production of injury can be recognised.

1. Rapid increase in the intensity of training, leading to overuse injuries.

2. Anatomical, especially the pronated foot, which may give rise to secondary defects in/the knee and spine.

3. Surface. Abrupt transition from sinking in sand to running on grass or on a hard road can produce injury in the anterior tibial muscles.

4. Terrain. A downhill slope can produce retropatellar pain, and an uphill slope an unexpected circulatory load, though there have been few fatalities reported from Sydney's "coronary hill".

5. Mechanics of running. In contrast to the bipedal gait of walking, with weight distributed evenly, running is basically on one leg at a time, involving a varus angulation at the hip and a valgus angulation at the sub-talar joint, worst in those who run with a crossover gait.

6. Shoes. Worn or otherwise unsuitable.

7. Premature resumption of training after injury. Overuse injury of the opposite leg may follow acute injury.

8. Exercise addiction may produce similar psychological problems to drug or tobacco addiction, and withdrawal symptoms occur during enforced rest.

INJURIES IN JOGGING may be classified by the anatomical area involved. Stress fractures can occur in any area of the lower leg, even with light training. Tenderness is localised, and pain gets worse as activity continues, and after it ceases. Radiography may show no detectable lesion for several weeks, until callus formation is visible.

If there are clinical grounds to suspect a stress fracture, its presence should be assumed until proved otherwise. In joggers the commonest sites are the second and third metatarsals, and the fibula, but may be found in the tarsal navicular in those who run on their toes, and in the tibia. They may be bilateral.

In the foot a variety of musculo-skeletal problems may be found; tendon involvement, traumatic synovitis of the metatarso-phalangeal joints and tenosynovitis especially of the tendons of the hallux.

"Jogger's heel" may involve bruising of the infracalcaneal fat pad, plantar fasciitis, calcaneal spur, and in children, apophysitis (Sever's disease).

Ankle lesions include haemarthrosis, tenosynovitis of any of the tendon sheaths around the joint, subluxation of the peroneal tendons, Achilles peritendonitis, and incomplete as well as complete ruptures of this large tendon, sometimes misdiagnosed as "sprained ankle". Rarely avulsion of the calcaneal insertion may occur. Talo-tibial exostoses may impinge during the forced dorsiflexion needed for running.

In the leg, tears of the gastrocnemius are common and recurrent problems, though hamstring tears are not common in joggers. The medial tibial compartment syndrome, ("Shinsplints") is also an uncommon jogging injury, though a major problem in other running events.

Knee injuries include patellar tendonitis, osteochondritis dissicans and simple synovitis. Gastrocnemius origin and hamstring insertion strains are troublesome. Rarely reported in the literature are popliteus insertion lesions, and reported more recently by several Scandinavian authors, (Orava 1978, Staff \& Nilsson 1980) the iliotibial band syndrome. 
In the thigh, muscle tears are uncommon amongst joggers, but muscle sheath tears with herniation are frequent, but insignificant. In the hip, trochanteric bursitis is very common. Avulsion fractures of the hamstring origin have been seen in young runners, as have avulsions of the sartorius origin. Osteoarthrosis of the hip joint is not infrequent among older joggers. Even after hip replacement, jogging may be resumed.

If jogging is worth its complications, two quotations may be remembered:

"It's a treat being a long-distance runner". (Alan Sillitoe)

"In the long run, we are all dead". (John Maynard Keynes).

\title{
REFERENCES
}

Orava, S., 1978. "Iliotibial tract syndrome in athletes." Brit.J. Sports Med. 12: 69-73.

Staff, P. H. and Nilsson, S., "Tendoperiostitis in the lateral femoral condyle in long-distance runners." Brit.J.Sports Med. 14: -

\section{TENDOPERIOSTITIS IN THE LATERAL FEMORAL CONDYLE IN LONG-DISTANCE RUNNERS}

\author{
P. H. STAFF, MD AND S. NILSSON, MD \\ Present address \\ Dept. of Physical Medicine and Rehabilitation, \\ Ulleval sykehus, OSLO 1, Norway
}

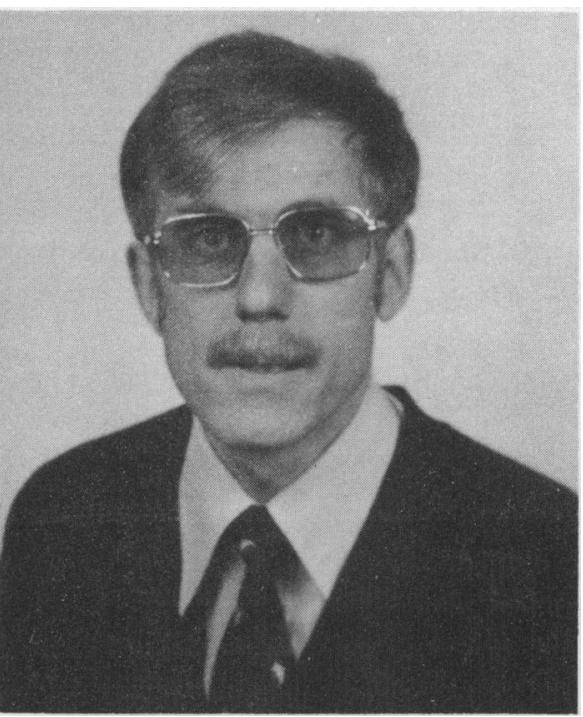

\section{INTRODUCTION}

Training for competitive sport is more intense today than ever before. It is therefore not surprising that sports medicine is faced with an increasing number of athletes with overuse injuries.

In Norway, long distance runners have consulted our sports clinic because they experienced pain located in the lateral aspect of the knee while training, especially in early spring and late autumn. Many doctors prescribe rest as the only therapy, but the athlete then discovers that the symptoms reappear as soon as he resumes training.

\section{SYMPTOMS}

The symptoms appear in runners training for endurance events. After 20-40 minutes of running they notice pain in the lateral side of one knee. The pain is of a dull aching type, vague at first but if running is continued it soon becomes so severe that further running is impossible.

When the symptoms are moderate, the pain is located in the lateral side of the knee, but it may spread to the upper part of the tibia and sometimes to the distal part of the thigh. As soon as running is stopped, the pain disappears. Some individuals, however, develop the symptoms quite rapidly, and experience difficulty even with walking.

Typically, running downhill often aggravates the symptoms, while running up-hill gives considerably less discomfort. Untreated, the symptoms can last for several months and thus more or less destroy a whole com- 